\title{
Update on the development of lurasidone as a treatment for patients with acute schizophrenia
}

\author{
This article was published in the following Dove Press journal: \\ Drug Design, Development and Therapy \\ 7 May 2012 \\ Number of times this article has been viewed
}

\author{
Norio Yasui-Furukori \\ Department of Neuropsychiatry, \\ Hirosaki University School \\ of Medicine, Aomori, Japan
}

Correspondence: Norio Yasui-Furukori Department of Neuropsychiatry, Hirosaki University School of Medicine, Hirosaki, Aomori 036-8562, Japan

Tel +8I I72395066

Fax +8I I72 395067

Email yasufuru@cc.hirosaki-u.ac.jp

\begin{abstract}
Lurasidone is a novel benzisothiazole antipsychotic drug for the treatment of schizophrenia. Of the antipsychotic drugs, lurasidone has the highest affinity for the 5-hydroxytryptamine (5-HT) $)_{7}$ receptor. Lurasidone also has high affinities for the dopamine $\mathrm{D}_{2}$, $5 \mathrm{HT}_{2 \mathrm{~A}}, 5-\mathrm{HT}_{1 \mathrm{~A}}$ and $\alpha_{2 \mathrm{C}}$ adrenergic receptors. Moreover, lurasidone has low affinities for the $\alpha_{1}$ adrenergic, histamine $\mathrm{H}_{1}$ and muscarinic $\mathrm{M}_{1}$ receptors. The involvement of 5- $\mathrm{HT}_{7}$ receptors in cognitive processes has been suggested by both pharmacological and molecular investigations. Chronic treatment with lurasidone increases neurotrophin BDNF mRNA levels in both the hippocampus (ventral and dorsal) and prefrontal cortex under basal conditions or in response to an acute swim stress. Lurasidone may potentiate N-methyl-D-aspartate receptor (NMDAR) function through antagonistic action on 5- $\mathrm{HT}_{7}$ receptors without a direct affinity for NMDARs. These results suggest that lurasidone treatment may be a novel approach for the prevention of the development of cognitive impairment in individuals who are at risk for schizophrenia or related disorders involving cognitive impairment. In clinical trials, treatment with lurasidone was associated with significantly greater endpoint improvement versus placebo on the Positive and Negative Syndrome Scale total score after 6 weeks among subjects receiving 80 or $160 \mathrm{mg}$. The most frequent side effects of lurasidone were akathisia, nausea, parkinsonism, dizziness and somnolence. Once-daily treatment with lurasidone at $160 \mathrm{mg}$ was superior to placebo based on the composite cognitive functioning measure. Lurasidone treatment produced improvements in Montgomery-Asberg Depression Rating Scale scores at 6 weeks that were significantly greater than placebo. A limitation of this review is that the majority of the data were obtained from abstracts and posters. These sources have not been subjected to the peer review processes of medical journals; thus, the results presented in these forums may require further quality review and subsequent revision prior to final publication.
\end{abstract}

Keywords: lurasidone, antipsychotic, schizophrenia, 5- $\mathrm{HT}_{7}$, cognition, BDNF

\section{Introduction}

Schizophrenia is a multidimensional and severely disabling psychiatric disease that strongly needs improved pharmacological interventions that produce better adherence, better long-term outcomes and better patient functionality. Symptom severity and the long-lasting, chronic patterns of schizophrenia often cause a high degree of disability. Support for the neurodevelopmental model of schizophrenia comes from a variety of research paradigms and suggests that cognitive abnormality is an independent, core feature of the illness. ${ }^{1-3}$

At the time of their first identified schizophrenic episode, patients have cognitive impairments with similar profiles and nearly identical severities as those of people with a more chronic course of the illness. ${ }^{4}$ Cognitive impairments are also observed prior 
to the onset of the full clinical syndrome (Figure 1), ${ }^{5-10}$ and deficits in multiple domains of cognition, including working memory, declarative memory, and executive function, often lead to severe functional impairment from the time of diagnosis. ${ }^{11,12}$ Abnormalities in the prefrontal cortex (PFC) and temporal cortex are considered to be the most likely basis of the cognitive impairments seen in schizophrenia. ${ }^{13,14}$ While there is evidence of cognitive deficits before the onset of the illness, there is limited knowledge as to when cognitive dysfunction emerges and how the subsequent deficits progress throughout childhood and adolescence.

Furthermore, in schizophrenia, mood symptoms seem to affect everyday functioning in a way that is unassociated with the severity of deficits in cognition and functional capacity. ${ }^{15}$ Depression in schizophrenia is no longer considered to be a phenomenon that only occurs during periods of partial recovery from psychosis. It is now widely known that depression occurs during all phases of the illness and affects everyday functioning (Figure 1). ${ }^{16}$

The aim of this review is to provide an update on the development of lurasidone treatment from the preclinical research data to the results of clinical trials in patients with schizophrenia.

\section{Pharmacodynamics}

Lurasidone is a novel benzoisothiazol antipsychotic drug (APD) that was approved for treatment of schizophrenia by the US Food and Drug Administration (FDA) in 2010. Figure 2 shows the receptor-binding profile of lurasidone. The signature receptor-binding profile of lurasidone is its high affinity for antagonistic action at the 5-hydroxytryptamine $(5-\mathrm{HT})_{7}$ receptor. The affinity of lurasidone for the $5-\mathrm{HT}_{7}$ receptor is the highest within its class of drugs. Lurasidone also has high affinity for the dopamine $\mathrm{D}_{2}, 5 \mathrm{HT}_{2 \mathrm{~A}}$ and other receptors associated with cognitive function (eg, 5- $\mathrm{HT}_{1 \mathrm{~A}}$ and $\alpha_{2 \mathrm{C}}$ ).
Moreover, lurasidone's weak affinity for the $\alpha 1$ adrenergic, histaminergic $\mathrm{H} 1$ or muscarinic M1 receptors suggests lower incidence of unpleasant side effects including cognitive deficits. Lurasidone's receptor profile suggests its potential to unlock procognitive action through serotonin receptors such as the $5-\mathrm{HT}_{7}$ and $5-\mathrm{HT}_{1 \mathrm{~A}}$ receptors. ${ }^{17-19}$ Clinical trials have shown that lurasidone is a safe and effective treatment for schizophrenia with minimal extrapyramidal, cardiovascular, or metabolic complications. ${ }^{20-25}$

\section{Animal models of cognition}

Although the molecular mechanism by which APDs improve cognition is not fully known, the involvement of $5-\mathrm{HT}_{7}$ receptors in cognitive processes has been suggested by both pharmacological and genetic tools. ${ }^{26,27}$ Lurasidone has been reported to improve acute MK-801-induced memory impairment in rats, ${ }^{28,29}$ as well as subchronic phencyclidine (PCP, a noncompetitive N-methyl-D-aspartate [NMDA] antagonist)-induced cognitive impairment in novel object recognition (NOR). ${ }^{30,31}$ In addition, lurasidone enhances performance in object retrieval with detour tasks (ORD), which have been used to test executive function in the common marmoset, a nonhuman primate. ${ }^{32}$ Recently, 5-HT 7 antagonism has been shown to contribute to the ability of lurasidone to improve NOR and the MK-801-induced impairment of learning and memory in the passive avoidance and Morris water-maze tests in rats. ${ }^{33-35}$

Pharmacologic early intervention during the 'prodromal' stage of schizophrenia, before positive and negative symptoms reach syndromal levels of severity, is a major goal of current strategies for improving outcome and minimizing the cost of these syndromes. ${ }^{36,37}$ Treatment of individuals in the prodromal period or at high risk for these disorders with atypical APDs has been reported to reduce the rate of progression to first-episode psychosis in some individuals. ${ }^{38,39}$

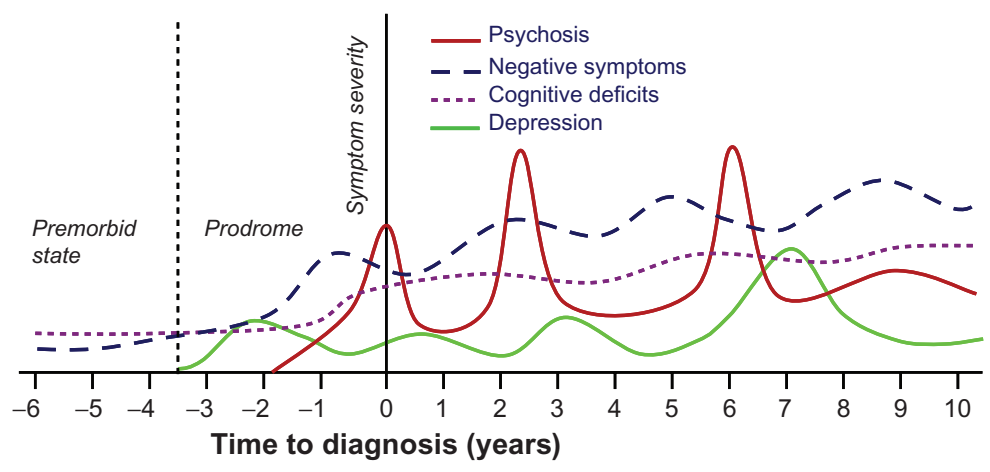

Figure I Schizophrenia progression.

Notes: Schizophrenia is characterized by positive symptoms (delusions and hallucinations), negative symptoms (eg, affective flattening, anhedonia, anergia), abnormalities in mood, and cognition deficits and often leads to severe functional impairment from the time of diagnosis. 


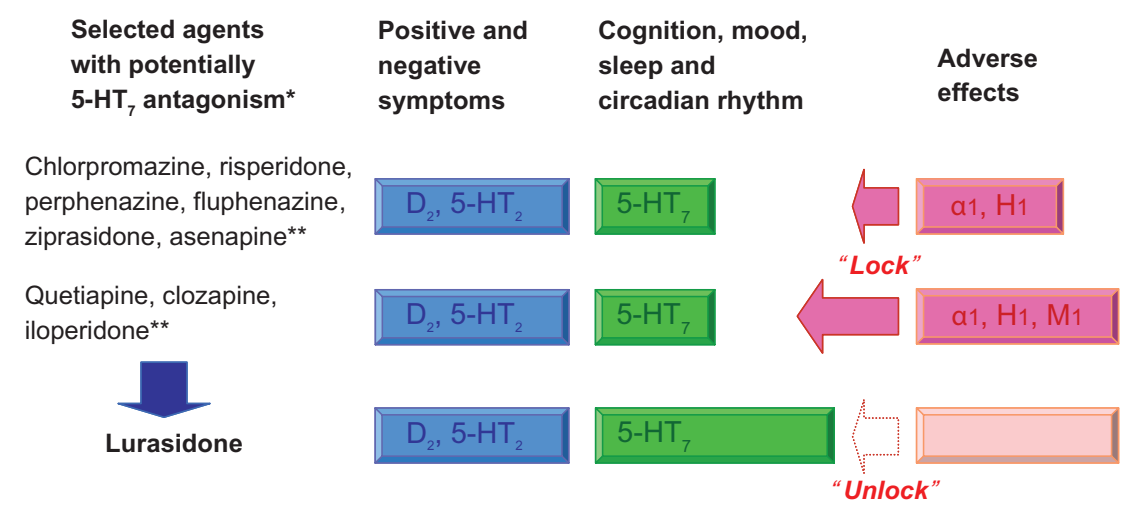

Figure 2 Receptor-binding profile of lurasidone showing the actions of lurasidone at key select receptors implicated in schizophrenia and its treatment. Notes: *PDSP Ki data available at http://pdsp.med.unc.edu/kidb.php; **US Package Insert. ${ }^{78}$

Lurasidone was administered along with PCP during the period in which the enduring deficits in NOR and other types of cognition are developing due to the cumulative effects of relatively low-dose PCP. Lurasidone prevented the development of PCP-induced cognitive impairment in NOR in rats. Subsequent subchronic treatment with lurasidone also had a long-lasting (2 weeks) ameliorative effect on PCP-induced NOR deficits. ${ }^{40}$ These results have given rise to the suggestion that lurasidone may be a novel approach for preventing the development of cognitive impairment in individuals who are at risk for schizophrenia or related disorders with cognitive impairment.

\section{Neuroadaptive changes: BDNF}

Inappropriate neurotrophic support during brain development could lead to a structural disorganization in which neuronal networks are established in a nonoptimal manner. Inadequate neurotrophic support in adult individuals could ultimately be an underlying mechanism that leads to a decreased capacity of the brain to adaptively change and an increased vulnerability to neurotoxic damage. Brain-derived neurotrophic factor (BDNF) is a mediator involved in neuronal survival, cellular resiliency and cellular plasticity in response to dopaminergic, cholinergic, and serotonergic inputs in the central nervous system. ${ }^{41}$

Chronic treatment with lurasidone increases neurotrophin BDNF mRNA levels in both the hippocampus (ventral and dorsal) and prefrontal cortex under basal conditions or in response to an acute swim stress. ${ }^{42,43}$ The adaptive changes under challenging conditions produced by repeated treatments with lurasidone may contribute to the amelioration of functional capacities and be closely associated with neuronal plasticity, both of which are deteriorated in patients with schizophrenia.

\section{Glutamatergic systems: NMDA receptors}

The first electrophysiological evidence showed that in vivo administration of lurasidone produces a significant enhancement of NMDA receptor-mediated excitatory postsynaptic currents (EPSC) in PFC neurons. Moreover, administration of a single dose of lurasidone restored NMDAR responses in subchronic PCP-treated rats. The selective 5- $\mathrm{HT}_{7}$ antagonist SB-269970 mimicked the enhancing effect of lurasidone on NMDAR-EPSC, while the $\mathrm{D}_{2}$ antagonist haloperidol (a typical APD) was ineffective. These results suggest that antagonism of $5-\mathrm{HT}_{7}$ receptors may contribute to the ability of lurasidone to potentiate NMDAR function. ${ }^{44}$ Biochemical evidence indicates that surface levels of the NR2A and NR2B subunits of the NMDA receptor are selectively and significantly elevated after lurasidone administration. Because the availability of NR2 subunits determines the number of functional NMDARs at synapses, these results suggest that the potential molecular mechanism underlying the enhancing effect of in vivo administration of lurasidone on NMDAR synaptic responses is the increased delivery or decreased internalization of synaptic NMDA receptors. ${ }^{44}$

These results suggest that lurasidone may potentiate NMDAR function through antagonistic actions on 5- $\mathrm{HT}_{7}$ receptors.

\section{Metabolomics}

The metabolomic "signature" of lurasidone has been investigated in a Phase III study using clinical blood samples obtained from patients with schizophrenia (ClinicalTrials. gov Identifier: NCT00615). Patterns of change in the metabolome can be interpreted as a molecular phenotype, either of a disease state or of the characteristic effect of a drug on an organism. In the lurasidone group, the serum 
levels of $3 \%$ of tested biochemicals were significantly changed. In contrast, $14 \%$ of biochemicals in groups receiving olanzapine were significantly changed. Treatment with lurasidone or olanzapine resulted in significantly increased serum levels of glutamate, glycine, and serine relative to placebo. ${ }^{45}$ Increases in blood glutamate were associated with improvements in negative symptoms among subjects responding to lurasidone treatment. Lurasidone-responders with high levels of improvement in negative symptoms had a significantly higher increase in glutamate levels compared to lurasidone-responders with low levels of improvement in negative symptoms. ${ }^{45}$

In this exploratory metabolomics analysis of schizophrenia responders, treatment with lurasidone did not have biochemically different effects than treatment with placebo, while treatment with olanzapine was associated with a higher proportion of distinct biochemical changes relative to placebo. These findings need to be confirmed using larger samples that include both treatment-responders and nonresponders. ${ }^{45}$ Data obtained from blood metabolomic profiling in the lurasidone clinical trial are consistent with the hypothesis that, based on its pharmacological profile, lurasidone treatment may be associated with enhanced glutamate activity.

\section{Depression}

Lurasidone has a high affinity for the $5-\mathrm{HT}_{7}$ receptor, to which it functions as an antagonist. Lurasidone also has a moderate affinity for the $5-\mathrm{HT}_{1 \mathrm{~A}}$ receptors, to which it functions as a partial agonist. Several lines of evidence have implicated both $5-\mathrm{HT}_{7}$ receptor antagonism and $5-\mathrm{HT}_{1 \mathrm{~A}}$ partial agonism as central mediators of antidepressant activity in animal behavioral models. ${ }^{46-49}$

Lurasidone has demonstrated antidepressant-like properties in olfactory bulbectomy models in rats. ${ }^{17}$ In addition, lurasidone reduced immobility, an antidepressant-like effect, in both the tail suspension and forced swim tests in wildtype $5-\mathrm{HT}_{7}^{+/+}$mice but not in $5-\mathrm{HT}_{7}^{-/-}$mice. Furthermore, the combination treatment of individually ineffective doses of lurasidone and citalopram (an antidepressant of the selective serotonin reuptake inhibitors [SSRIs] group) also induced an antidepressant-like response in both tests. In the repeated open-space swim model, which is a model of depression requiring chronic treatment, lurasidone had antidepressant effects that were similar to citalopram in magnitude. ${ }^{50}$ The results from the acute mouse models suggest that the antidepressant effect of lurasidone require functional 5- $\mathrm{HT}_{7}$ receptors. Though lurasidone lacks monoamine reuptake-inhibiting effects, the high $5-\mathrm{HT}_{7}$ receptor affinity of lurasidone can synergistically interact with SSRIs to provide antidepressant-like effects that require the $5-\mathrm{HT}_{7}$ receptors.

\section{Clinical developments: short-term trials}

Comprehensive review of Phase II/III data evaluating the efficacy and safety of lurasidone in short-term schizophrenia treatment trials is published in several articles. ${ }^{23-25,51,52}$

Three multinational, 6-week, double-blind, placebo- and active comparator-controlled, randomized Phase III studies have been completed, two of which formed the basis for the approval of the drug by the FDA. ${ }^{24}$ The third Phase III trial (PEARL 3, ClinicalTrials.gov Identifier: NCT00790192) was completed after the New Drug Application was submitted in 2011. The PEARL 3 was the only pivotal trial that included the highest clinical dose of $160 \mathrm{mg} /$ day with a 3-day initial titration from $120 \mathrm{mg} /$ day.

The primary measure of endpoint efficacy in all three Phase III trials was the mean change in the Positive and Negative Symptoms of Schizophrenia Scale (PANSS) total score from baseline to endpoint. A key secondary endpoint was the change in the Clinical Global Impression of Severity scale (CGI-S). The PEARL 3 was the only trial that evaluated cognitive efficacy with a computerized system and the University of California San Diego (UCSD) Performancebased Skills Assessment, Brief (UPSA-B), which assesses the capacity for functioning. ${ }^{53}$

\section{PEARL 3: efficacy and safety}

The efficacy and safety of lurasidone $(80 \mathrm{mg} /$ day and $160 \mathrm{mg} /$ day) in patients with an acute exacerbation of schizophrenia was evaluated in hospitalized patients who met the DSM-IV criteria for schizophrenia (PANSS total score $>80$ ). Patients were randomized in a 6-week, double-blind study in which they were treated with lurasidone at $80 \mathrm{mg}$ or $160 \mathrm{mg}$, quetiapine XR $600 \mathrm{mg}$ (QXR; included to confirm assay sensitivity), or placebo, administered once-daily in the evening. Outcome measures included the PANSS, CGI-S, the Montgomery-Asberg Depression Rating Scale (MADRS), and the Epworth Sleepiness Scale (ESS).

Treatments with lurasidone were associated with significantly greater endpoint improvements at 6 weeks on the PANSS total score vs placebo $(-10.3)$ among subjects in the $80 \mathrm{mg}(-22.2 ; P<0.001)$ and $160 \mathrm{mg}(-26.5$; $P<0.001)$ dosage groups. Significant endpoint improvement was observed in both the CGI-S versus placebo $(-0.9)$ during treatment with either $80(-1.5 ; P<0.001)$ or $160 \mathrm{mg}$ 
$(-1.7 ; P<0.001)$ doses of lurasidone. Significant differences in PANSS total scores occurred between the lurasidone treatment groups and placebo by Day 4. QXR produced significantly greater endpoint improvement than placebo on the PANSS total score $(-27.8$ vs $-10.3 ; P<0.001)$ and the CGI-S $(-1.7$ vs $-0.9 ; P<0.001)$. Significant improvements in PANSS total scores were found at day 4 and all subsequent study visits for both lurasidone groups. ${ }^{53}$

In this study, treatments with once-daily lurasidone at doses of $80 \mathrm{mg}$ or $160 \mathrm{mg}$ were not associated with doserelated increases in adverse events or adverse event-related discontinuations. The most frequent events on lurasidone were akathisia, nausea, parkinsonism, dizziness, and somnolence (all occurred in $<10 \%$ of subjects, Table 1 ). In the placebo-controlled trials with lurasidone up to $120 \mathrm{mg} / \mathrm{day}$, akathisia was a dose-related adverse event. ${ }^{21,54}$ However, the incidence of akathisia in patients receiving lurasidone at $160 \mathrm{mg} /$ day was not a dose-related adverse event. ${ }^{53}$ Akathisia is a common side effect of drugs like antipsychotics and SSRIs, but it also occurs spontaneously in patients with Parkinson's disease. Several lines of evidence suggest that akathisia can be attributed to low activity of the dopaminergic projections from the midbrain to the ventral striatum. However, the exact pathophysiological mechanism of this extrapyramidal symptom remains unclear. ${ }^{55}$

Treatments with lurasidone at $80 \mathrm{mg}$ and $160 \mathrm{mg}$ were associated with mean increases in weight that were not significantly different from placebo $(+0.6 \mathrm{~kg}$ and $+0.6 \mathrm{~kg}$ vs $+0.1 \mathrm{~kg}$, respectively); however, the mean increase in weight was higher vs placebo for QXR $(+2.1 \mathrm{~kg}){ }^{55}$ Total cholesterol and triglycerides were decreased at endpoint on both doses of lurasidone but were increased on QXR. ${ }^{55}$

The above data support the results of a post hoc analysis of the data from PEARL 2. In this analysis, the 6-week olanzapine-controlled study found that lurasidone and placebo had similar acute effects on 10-year Framingham coronary heart disease (CHD) risk scores, while olanzapine was associated with higher risks than placebo in male patients. ${ }^{23,56}$

Treatments with $80 \mathrm{mg}$ or $160 \mathrm{mg}$ of lurasidone administered once-daily in the evening were associated with reductions in daytime sleepiness that were similar in magnitude to placebo. In contrast, treatment with QXR $600 \mathrm{mg}$ was associated with a significant increase in self-reported daytime sleepiness (based on ESS assessment) compared to placebo. ${ }^{55}$ These findings indicate overall daytime sleepiness might be a mediator of change in clinical or performancebased functional outcomes, while sleepiness as a mediator of cognitive performance is more dependent on the specific situation for which sleepiness is reported.

\section{PEARL 3: cognition}

The results of the large-scale CATIE study suggested that atypical antipsychotic medications may not have

Table I Most common adverse events ( $\geq 5 \%$ and $\geq 2 \times$ placebo) in two acute schizophrenia studies

\begin{tabular}{|c|c|c|c|c|c|c|c|c|}
\hline \multirow[t]{2}{*}{ Preferred term } & \multicolumn{4}{|c|}{ PEARL 2 study ${ }^{21}$} & \multicolumn{4}{|c|}{ PEARL 3 study ${ }^{53}$} \\
\hline & $\begin{array}{l}\text { LUR } \\
40 \mathrm{mg} / \mathrm{d} \\
(\mathrm{n}=119)\end{array}$ & $\begin{array}{l}\text { LUR } \\
120 \mathrm{mg} / \mathrm{d} \\
(\mathrm{n}=|| 8)\end{array}$ & $\begin{array}{l}\text { OLA } \\
15 \mathrm{mg} / \mathrm{d} \\
(\mathrm{n}=122)\end{array}$ & $\begin{array}{l}\text { Placebo } \\
(n=|| 6)\end{array}$ & $\begin{array}{l}\text { LUR } \\
80 \mathrm{mg} / \mathrm{d} \\
(\mathrm{n}=125)\end{array}$ & $\begin{array}{l}\text { LUR } \\
160 \mathrm{mg} / \mathrm{d} \\
(\mathrm{n}=121)\end{array}$ & $\begin{array}{l}\text { QXR } \\
600 \mathrm{mg} / \mathrm{d} \\
(\mathrm{n}=119)\end{array}$ & $\begin{array}{l}\text { Placebo } \\
(n=|2|)\end{array}$ \\
\hline Akathisia & 14 (II.8) & $27(22.9)$ & $9(7.4)$ & I $(0.9)$ & $10(8.0)$ & $9(7.4)$ & $2(1.7)$ & $\mathrm{I}(0.8)$ \\
\hline Somnolence & $12(10.1)$ & $18(15.3)$ & II (9.0) & $5(4.3)$ & $5(4.0)$ & $8(6.6)$ & $16(13.4)$ & $\mathrm{I}(0.8)$ \\
\hline Sedation & II (9.2) & $16(13.6)$ & $18(14.8)$ & $4(3.4)$ & - & - & - & - \\
\hline Parkinsonism & II (9.2) & $13(11.0)$ & $6(4.9)$ & $2(1.7)$ & $7(5.6)$ & $8(6.6)$ & $4(3.4)$ & 0 \\
\hline Nausea & $13(10.9)$ & $9(7.6)$ & $6(4.9)$ & $5(4.3)$ & $10(8.0)$ & $8(6.6)$ & $4(3.4)$ & $4(3.3)$ \\
\hline Weight increase & $2(1.7)$ & $2(1.7)$ & $25(20.5)$ & $6(5.2)$ & I (0.8) & $2(1.7)$ & $8(6.7)$ & $\mathrm{I}(0.8)$ \\
\hline Dystonia & $4(3.4)$ & $9(7.6)$ & I $(0.8)$ & I (0.9) & - & - & - & - \\
\hline Agitation & $14(11.8)$ & $7(5.9)$ & $8(6.6)$ & $6(5.2)$ & - & - & - & - \\
\hline Dizziness & $5(4.2)$ & $6(5.1)$ & $3(2.5)$ & $2(1.7)$ & $6(4.8)$ & $7(5.8)$ & $16(13.4)$ & $2(1.7)$ \\
\hline Restlessness & $7(5.9)$ & $4(3.4)$ & $4(3.3)$ & $3(2.6)$ & - & - & - & - \\
\hline Salivary hypersecretion & $2(1.7)$ & $8(6.8)$ & $\mathrm{I}(0.8)$ & $0(0.0)$ & - & - & - & - \\
\hline Musculoskeletal stiffness & $3(2.5)$ & $6(5.1)$ & $3(2.5)$ & $2(1.7)$ & - & - & - & - \\
\hline Appetite decreased & $6(5.0)$ & $\mathrm{I}(0.8)$ & $2(1.6)$ & $2(1.7)$ & - & - & - & - \\
\hline Dry mouth & $2(1.7)$ & $3(2.5)$ & $12(9.8)$ & $\mathrm{I}(0.9)$ & $2(1.6)$ & $2(1.7)$ & $9(7.6)$ & $\mathrm{I}(0.8)$ \\
\hline Constipation & - & - & - & - & $3(2.4)$ & $\mathrm{I}(0.8)$ & $8(6.7)$ & $3(2.5)$ \\
\hline Arthralgia & - & - & - & - & $2(1.8)$ & $\mathrm{I}(0.8)$ & $7(5.9)$ & $\mathrm{I}(0.8)$ \\
\hline URI & - & - & - & - & $2(1.6)$ & I (0.8) & $6(5.0)$ & $\mathrm{I}(0.8)$ \\
\hline
\end{tabular}

Note: Data shows number of patients (\%).

Abbreviations: LUR, lurasidone; OLA, olanzapine; QXR, quetiapine XR; URI, upper respiratory tract infection. 
beneficial effects on cognition..$^{57,58}$ However, the CATIE trial specifically recruited clinically stable patients, did not include placebo controls, and did not require fixed doses of antipsychotic medications. This study examined cognitive functioning in initially unstable patients with schizophrenia (PANSS total score at baseline: mean $=97.4, \mathrm{SD}=10.5$, $\mathrm{N}=482) .{ }^{59}$ Both cognitive performance and UPSA-B were examined at acute phase baseline after 6 weeks and at 3 and 6 months in the flexible-dose extension phase of double-blind treatment with QXR.

Once-daily treatment with lurasidone at $160 \mathrm{mg}$ was superior to both placebo $(P<0.05, \mathrm{~d}=0.25)$ and QXR treatment $(P<0.05, \mathrm{~d}=0.28)$ on the composite cognitive functioning measure, while QXR, lurasidone $80 \mathrm{mg}$, and placebo did not differ from each other. UPSA-B scores were also superior to placebo at the 6-week endpoint for all active treatments. The lurasidone benefit over QXR was sustained $(d=0.25)$ at the 6-month endpoint. ${ }^{59}$

This is the first pharmacological study to date in which the investigational treatment was superior to placebo on cognitive assessments and a functional co-primary measure (UPSA-B) at a 6-week endpoint, as well as to demonstrate superiority to an active comparator on neurocognitive improvement over an initial 6-week acute phase and subsequently over a 6-month extension study period. These findings will require replication, but cannot be attributed to practice effects because of the placebo corrections.

\section{PEARL 3: depression}

Both doses of lurasidone and QXR produced significantly $(P<0.001)$ greater improvements in MADRS scores than placebo at the 6-week endpoint. ${ }^{55}$

In Study D1050196, lurasidone ( $80 \mathrm{mg} /$ day) demonstrated significant efficacy compared to placebo on the MADRS in acute patients with schizophrenia. Lurasidone also demonstrated significant effects in a post hoc analysis of the subgroup of patients ( $62.8 \%$ of total intent-to-treat population) with elevated levels of depressive symptomatology (baseline MADRS $\geq 12$; mean $=18.7$ ). The effect size was 0.44 (MADRS change at 6 -week endpoint; $P=0.033$ ). ${ }^{20}$ Lurasidone $(80 \mathrm{mg} /$ day) demonstrated replicable significant improvements in the MADRS.

\section{Summary}

Schizophrenia is a major public health problem and a burden on families and the community. It tends to be a lifelong disorder requiring multimodal treatments and support at all stages of illness. The cause of the illness is still unknown. Current treatments focus on eliminating symptoms with antipsychotic medications and various psychosocial treatments.

In schizophrenia, neurocognition is the most robust predictor of current functional status. ${ }^{60-62}$ In fact, some research suggests that neurocognition is more consistently related to functioning than symptom severity. ${ }^{63,64}$ Even in the prodromal phase, before the onset of frank psychosis, cognitive deficits significantly predict subsequent diagnosis. ${ }^{65}$

The current predominant dopamine hypothesis of schizophrenia might be characterized by an imbalance between subcortical and cortical dopamine systems, based on functional brain imaging study in altered PFC functions and preclinical studies emerged the importance of prefrontal dopamine transmission at $\mathrm{D}_{1}$ receptors (the main dopamine receptor in the neocortex) for optimal PFC performance. ${ }^{66,67}$ The subcortical mesolimbic dopamine projections might be hyperactive, resulting in hyperstimulation of $\mathrm{D}_{2}$ receptors and positive symptoms, while mesocortical dopamine projections to the PFC might be hypoactive, resulting in hypostimulation of $\mathrm{D}_{1}$ receptors in $\mathrm{PFC}$ which might be implicated in the cognitive impairments and negative symptoms of schizophrenia. ${ }^{68,69}$ The $5-\mathrm{HT}_{7}$ receptor antagonist prevents the inhibition of dopamine neuronal firing activity induced by amphetamine in the ventral tegmental area, but not in the substantia nigra pars compacta. This suggests that $5-\mathrm{HT}_{7}$ receptors modulate preferentially the mesocorticolimbic pathway. ${ }^{70}$

Over the last several years, a number of studies have attempted to evaluate the role of the 5- $\mathrm{HT}_{7}$ receptor in psychiatric and neurological disorders. For most of these disorders, the results have been mixed with inconsistencies between species and the pharmacological and genetic manipulations performed. ${ }^{71}$ Possible reasons for these discrepancies are differences in the type and concentration of drug administered, timing and site (systemic or central) of administration, type of behavioral test, interaction with other neurotransmission systems. ${ }^{72-74}$ Nevertheless, the research conducted so far, and reported in this paper, suggests an important participation of 5- $\mathrm{HT}_{7}$ receptors on cognitive functions, treatment of cognitive disorders, considering the ability of antipsychotic and antidepressant drugs to interact with the $5-\mathrm{HT}_{7}$ receptor.

The $5-\mathrm{HT}_{7}$ receptor is one of the most recently discovered 5 -HT receptors. The highest density of $5-\mathrm{HT}_{7}$ receptor expression in the brain has been described in the hypothalamus, thalamus, hippocampus, and frontal cortex. ${ }^{75-77}$ This widespread central distribution suggests multiple roles in circadian rhythm, thermoregulation, sleep, affective disorders, and is important for cognitive functions. 
In vivo lurasidone administration selectively increases the surface level of NMDAR NR2 subunits, which may account for the potentiation of NMDAR-mediated synaptic responses in the frontal cortex. The $5-\mathrm{HT}_{7}$ receptor is one of the potential receptors underlying the enhancement of NMDAR-EPSCs by lurasidone. Lurasidone is capable of reversing the NMDAR hypofunction induced by repeated PCP treatment, which is a widely studied animal model of schizophrenia. ${ }^{44}$ Moreover, the ability of lurasidone to reverse the PCP-induced NOR deficit is blocked by the $5-\mathrm{HT}_{7}$ agonist AS19. ${ }^{33}$ Repeated exposure to lurasidone increases the mRNA and protein levels of BDNF, an important determinant of the synaptic plasticity of glutamatergic synapses. ${ }^{42}$

In the PEARL 3 study, lurasidone administered oncedaily in the evening at $80 \mathrm{mg}$ and $160 \mathrm{mg}$ demonstrated superiority compared to placebo in terms of PANSS total scores. Significant improvements were demonstrated at day 4 and at all subsequent study visits. Lurasidone was well-tolerated, displaying no clinically significant dose-related increase in adverse events. Treatment with lurasidone was associated with minimal changes in metabolic parameters. Significant increases in weight and lipids were observed for QXR compared to placebo. In addition, lurasidone demonstrated significant improvements that were superior to placebo on both cognitive assessments and a functional measure (UPSA-B) at a 6-week endpoint. Lurasidone also demonstrated superiority to an active comparator on neurocognitive improvement over an initial 6-week acute phase and subsequently over a 6-month extension study period.

The known receptor-binding profile, in combination with animal model evidence and data from schizophrenia trials indicating improvement in cognitive functioning and depressive symptoms, suggests the potential for precognitive and antidepressant efficacy of lurasidone in patients with schizophrenia.

Cognitive function in schizophrenia is one of the most critical determinants of quality of life and function in schizophrenia. Lurasidone may be functionally effective for the treatment of schizophrenia with underlying cognitive dysfunctions and associated comorbid depression. Further, lurasidone may have the potential to alter the trajectory of the illness for those at highest risk and reduce the burden on individuals and their families.

Overall, lurasidone at a once-daily dose in the range of 40-160 mg was well-tolerated and produced no clinically significant dose-related increases in adverse events. This was true even at a dose of $160 \mathrm{mg}$, which is above the recommended maximum dose of $80 \mathrm{mg} /$ day in the
US package insert. Treatment with lurasidone was associated with a relatively low incidence of extrapyramidal symptoms. Furthermore, lurasidone was associated with low potentials for weight gain, daytime sleepiness, adverse metabolic or QTc effects, and minimal effects on prolactin.

A limitation of this review is that the majority of the data were obtained from abstracts and posters. These sources have not been subjected to the peer review processes of medical journals, and the results presented in these forums may be subject to further quality review and subsequent revision prior to final publication.

The product label is the most authoritative source of information on lurasidone. ${ }^{78}$ The current labeling for lurasidone recommends doses of $40-80 \mathrm{mg} /$ day, and additional data from the PEARL 3 study showing the efficacy of $160 \mathrm{mg} /$ day doses are under review by the FDA.

The effectiveness of lurasidone in schizophrenia beyond six weeks has not been clarified in controlled studies. Other therapeutic properties of lurasidone for the treatment of acute bipolar depression (as a monotherapy and an adjunctive therapy) and maintenance trials are being evaluated. In addition, two trials for the treatment of major depressive disorder with mixed features as discussed in the DSM-5 Mood Disorders Work Group have been registered at http://www.clinicaltrials.gov. Another registration Phase III trial for treatment of schizophrenia is under way in Japan.

\section{Disclosure}

Dr Yasui-Furukori reports no conflicts of interest in this work.

\section{References}

1. Gold JM. Cognitive deficits as treatment targets in schizophrenia. Schizophr Res. 2004;72(1):21-28.

2. Green MF, Kern RS, Heaton RK. Longitudinal studies of cognition and functional outcome in schizophrenia: implications for MATRICS. Schizophr Res. 2004;72(1):41-51.

3. Elvevåg B, Goldberg TE. Cognitive impairment in schizophrenia is the core of the disorder. Crit Rev Neurobiol. 2000;14(1):1-21.

4. Harvey PD. When does cognitive decline occur in the period prior to the first episode of schizophrenia? Psychiatry (Edgmont). 2009;6(7):12-14.

5. Lieberman JA, Perkins D, Belger A, et al. The early stages of schizophrenia: speculations on pathogenesis, pathophysiology, and therapeutic approaches. Biol Psychiatry. 2001;50(11):884-897. Erratum in: Biol Psychiatry. 2002;51(4):346.

6. Cannon TD, Bearden CE, Hollister JM, Rosso IM, Sanchez LE, Hadley T. Childhood cognitive functioning in schizophrenia patients and their unaffected siblings: a prospective cohort study. Schizophr Bull. 2000;26:379-393.

7. Jones P, Rodgers B, Murray R, Marmot M. Child development risk factors for adult schizophrenia in the British 1946 birth cohort. Lancet. 1994;344:1398-1402. 
8. Lencz T, Smith C, McLaughlin D, et al. Generalized and specific neurocognitive deficits in prodromal schizophrenia. Biol Psychiatry. 2006;59:863-871.

9. McGlashan TH, Hoffman RE. Schizophrenia as a disorder of developmentally reduced synaptic connectivity. Arch Gen Psychiatry. 2000;57:637-648.

10. Niendam TA, Bearden CE, Rosso IM, et al. A prospective study of childhood neurocognitive functioning in schizophrenic patients and their siblings. Am J Psychiatry. 2003;160:2060-2062.

11. Gold JM. Is cognitive impairment in schizophrenia ready for diagnostic prime time? World Psychiatry. 2008;7:32-33.

12. Sawa A, Snyder SH. Schizophrenia: diverse approaches to a complex disease. Science. 2002;296:692-695.

13. Weinberger DR, Berman KF, Zec RF. Physiologic dysfunction of dorsolateral prefrontal cortex in schizophrenia. I. Regional cerebral blood flow evidence. Arch Gen Psychiatry. 1986;43:114-124.

14. Ragland JD, Laird AR, Ranganath C, Blumenfeld RS, Gonzales SM, Glahn DC. Prefrontal activation deficits during episodic memory in schizophrenia. Am J Psychiatry. 2009;166:863-874.

15. Harvey PD. Mood symptoms, cognition, and everyday functioning: in major depression, bipolar disorder, and schizophrenia. Innov Clin Neurosci. 2011;8(10):14-18.

16. Bowie CR, Leung WW, Reichenberg A, et al. Predicting schizophrenia patients' real-world behavior with specific neuropsychological and functional capacity measures. Biol Psychiatry. 2008;63(5):505-511. Epub July 27, 2007.

17. Ishibashi T, Horisawa T, Tokuda K, et al. Pharmacological profile of lurasidone, a novel antipsychotic agent with potent 5-hydroxytryptamine 7 (5-HT7) and 5-HT1A receptor activity. J Pharmacol Exp Ther. 2010;334(1):171-181.

18. Meyer JM, Loebel AD, Schweizer E. Lurasidone: a new drug in development for schizophrenia. Expert Opin Investig Drugs. 2009;18(11): 1715-1726.

19. Stahl SM. The serotonin-7 receptor as a novel therapeutic target. J Clin Psychiatry. 2010;71(11):1414-1415.

20. Nakamura M, Ogasa M, Guarino J, et al. Lurasidone in the treatment of acute schizophrenia: a double-blind, placebo-controlled trial. J Clin Psychiatry. 2009;70(6):829-836.

21. Meltzer HY, Cucchiaro J, Silva R, et al. Lurasidone in the treatment of schizophrenia: a randomized, double-blind, placeboand olanzapinecontrolled study. Am J Psychiatry. 2011;168(9): 957-967.

22. Potkin SG, Ogasa M, Cucchiaro J, et al. Double-blind comparison of the safety and efficacy of lurasidone and ziprasidone in clinically stable outpatients with schizophrenia or schizoaffective disorder. Schizophr Res. 2011;132(2-3):101-107.

23. Kane JM. Lurasidone: a clinical overview. J Clin Psychiatry. 2011;72(Suppl 1):24-28.

24. Citrome L. Lurasidone for schizophrenia: a brief review of a new second-generation antipsychotic. Clin Schizophr Relat Psychoses. 2011;4(4):251-257.

25. Citrome L. Lurasidone for schizophrenia: a review of the efficacy and safety profile for this newly approved second-generation antipsychotic. Int J Clin Pract. 2011;65(2):189-210.

26. Roberts AJ, Hedlund PB. The 5-HT(7) receptor in learning and memory. Hippocampus. April 11, 2011. [Epub ahead of print.]

27. Nikiforuk A. Selective blockade of 5-HT7 receptors facilitates attentional set-shifting in stressed and control rats. Behav Brain Res. 2012;226(1):118-123.

28. Ishiyama T, Tokuda K, Ishibashi T, et al. Lurasidone (SM-13496), a novel atypical antipsychotic drug, reverses MK-801-induced impairment of learning and memory in the rat passive-avoidance test. Eur $J$ Pharmacol. 2007;572(2-3):160-170.

29. Enomoto T, Ishibashi T, Tokuda K, et al. Lurasidone reverses MK-801-induced impairment of learning and memory in the Morris water maze and radial-arm maze tests in rats. Behav Brain Res. 2008;186(2):197-207.
30. Horiguchi M, Huang M, Meltzer HY. The role of 5-hydroxytryptamine 7 receptors in the phencyclidine-induced novel object recognition deficit in rats. J Pharmacol Exp Ther. 2011;338(2):605-614.

31. Meltzer HY, Horiguchi M, Massey BW. The role of serotonin in the NMDA receptor antagonist models of psychosis and cognitive impairment. Psychopharmacology (Berl). 2011;213(2-3):289-305.

32. Kazuhito Ikeda K, Murai T, Tsujimura T, et al. A unique cognitive enhancing effect of lurasidone in object retrieval with detours, a test of executive function in non-human primates. Poster presented at the 40th annual meeting of Society for Neuroscience; Nov 2010; San Diego, CA.

33. Horiguchi M, Huang M, Meltzer HY. The role of 5-hydroxytryptamine 7 receptors in the phencyclidine-induced novel object recognition deficit in rats. J Pharmacol Exp Ther. 2011;338(2):605-614.

34. Horiguchi $\mathrm{M}$, Huang $\mathrm{M}$, Meltzer HY. Interaction of $\mathrm{mGlu}^{2 / 3}$ agonism with clozapine and lurasidone to restore novel object recognition in subchronic phencyclidine-treated rats. Psychopharmacology (Berl). 2011;217(1):13-24.

35. Horisawa T, Ishibashi T, Nishikawa H, et al. The effects of selective antagonists of serotonin 5-HT7 and 5-HT1A receptors on MK-801induced impairment of learning and memory in the passive avoidance and Morris water maze tests in rats: mechanistic implications for the beneficial effects of the novel atypical antipsychotic lurasidone. Behav Brain Res. 2011;220(1):83-90.

36. Bilder RM, Lipschutz-Broch L, Reiter G, Geisler SH, Mayerhoff DI, Lieberman JA. Intellectual deficits in first-episode schizophrenia: evidence for progressive deterioration. Schizophr Bull. 1992;18(3):437-448.

37. Klosterkötter J, Hellmich M, Steinmeyer EM, Schultze-Lutter F. Diagnosing schizophrenia in the initial prodromal phase. Arch Gen Psychiatry. 2001;58(2):158-164.

38. Ruhrmann S, Schultze-Lutter F, Bechdolf A, Klosterkötter J. Intervention in at-risk states for developing psychosis. Eur Arch Psychiatry Clin Neurosci. 2010;260(Suppl 2):S90-S94.

39. Kaur T, Cadenhead KS. Treatment implications of the schizophrenia prodrome. Curr Top Behav Neurosci. 2010;4:97-121.

40. Horiguchi M, Meltzer HY. Co-treatment with the atypical antipsychotic drug (APD) lurasidone, or the 5-HT1A agonist, tandospirone, prevents the phencyclidine (PCP)-induced impairment in novel object recognition (NOR) in female rats. Poster presented at Neuroscience 2011, the 41st Annual Meeting of Society for Neuroscience; Nov 2011; Washington, DC.

41. Angelucci F, Brenè S, Mathé AA. BDNF in schizophrenia, depression and corresponding animal models. Mol Psychiatry. 2005;10(4):345-352.

42. Fumagalli F, Calabrese F, Luoni A, Bolis F, Racagni G, Riva MA. Modulation of BDNF expression by repeated treatment with the novel antipsychotic lurasidone under basal condition and in response to acute stress. Int J Neuropsychopharmacol. 2012;15(2):235-246.

43. Luoni A, Fumagalli F, Calabrese F, Ogasa M, Racagni G, Riva MA. Modulation of neurotrophic mechanisms after chronic treatment with the novel antipsychotic lurasidone in rat. Poster presented at the 24th European College of Neuropsychopharmacology Congress; Sep 2011; Paris, France.

44. Yuen EY, Li X, Wei J, Horiguchi M, Meltzer HY, Yan Z. The novel antipsychotic drug lurasidone enhances NMDA receptor-mediated synaptic responses. Mol Pharmacol. 2012;81(2):113-119.

45. Potkin SG, Silva R, Cucchiaro J. Metabolomic correlates of response in patients with schizophrenia treated with lurasidone. Poster presented at the 164th Annual Meeting of the American Psychiatric Association; May 2011; Honolulu, HI.

46. Newman-Tancredi A. The importance of 5-HT1A receptor agonism in antipsychotic drug action: rationale and perspectives. Curr Opin Investig Drugs. 2010;11(7):802-812.

47. Guscott M, Bristow LJ, Hadingham K, et al. Genetic knockout and pharmacological blockade studies of the 5-HT7 receptor suggest therapeutic potential in depression. Neuropharmacology. 2005;48(4): 492-502. 
48. Hedlund PB, Huitron-Resendiz S, Henriksen SJ, Sutcliffe JG. 5-HT7 receptor inhibition and inactivation induce antidepressantlike behavior and sleep pattern. Biol Psychiatry. 2005;58(10):831-837.

49. Hedlund PB. The 5-HT7 receptor and disorders of the nervous system: an overview. Psychopharmacology (Berl). 2009;206(3):345-354.

50. Hedlund PB, Cates L, Roberts AJ, Huitron-Resendiz S. The antidepressant-like effects of lurasidone are mediated by the 5-HT7 receptor. Poster presented at Neuroscience 2011, the 41st Annual Meeting of Society for Neuroscience; Nov 2011; Washington, DC.

51. Samalin L, Garnier M, Llorca PM. Clinical potential of lurasidone in the management of schizophrenia. Ther Clin Risk Manag. 2011;7:239-250

52. Owen RT. Lurasidone: a new treatment option for schizophrenia. Drugs Today (Barc). 2011;47(11):807-816.

53. Loebel A, Cucchiaro J, Sarma K, et al. Lurasidone in the treatment of acute schizophrenia: results of the double-blind, placebo-controlled, 6-week, Pearl 3 trial. Poster presented at the 164th Annual Meeting of the American Psychiatric Association; May 2011; Honolulu, HI.

54. Latuda [prescribing information]. Marlborough, MA: Sunovion Pharmaceuticals; Dec 2011 Available from: http://www.latuda.com/ LatudaPrescribingInformation.pdf. Accessed December 20, 2011.

55. Stahl SM, Lonnen AJ. The mechanism of drug-induced akathsia. CNS Spectr. January 15, 2011. [Epub ahead of print.]

56. Newcomer JW, Pikalov A, Cucchiaro J, et al. Impact of lurasidone and olanzapine on Framingham ten year coronary heart disease risk estimate in schizophrenia. Presented at the 164th Annual Meeting of the American Psychiatric Association; May 2011; Honolulu, HI.

57. Keefe RS, Bilder RM, Davis SM, et al; CATIE Investigators; Neurocognitive Working Group. Neurocognitive effects of antipsychotic medications in patients with chronic schizophrenia in the CATIE trial. Arch Gen Psychiatry. 2007;64:633-647.

58. Hill SK, Bishop JR, Palumbo D, Sweeney JA. Effect of second-generation antipsychotics on cognition: current issues and future challenges. Expert Rev Neurother. 2010;10:43-57.

59. Harvey P, Siu C, Cucchiaro J, Pikalov A, Maruff P, Loebel A. Cognitive performance in patients with schizophrenia treated with lurasidone: Results from a placebo and active-controlled acute phase study followed by a 6 month double-blind extension. Poster presented at the 50th Annual Meeting of American College of Neuropsychopharmacology; Dec 2011; Waikoloa Beach, HI.

60. Green MF. What are the functional consequences of neurocognitive deficits in schizophrenia? Am J Psychiatry. 1996;153(3):321-330.

61. Bowie CR, Leung WW, Reichenberg A, et al. Predicting schizophrenia patients' real-world behavior with specific neuropsychological and functional capacity measures. Biol Psychiatry. 2008;63:505-551.

62. Harvey PD, Lombardi J, Leibman M, et al. Age-related differences in formal thought disorder in chronically hospitalized schizophrenic patients: a cross-sectional study across nine decades. Am J Psychiatry. 1997;154(2):205-210
63. Kurtz MM. Symptoms versus neurocognitive skills as correlates of everyday functioning in severe mental illness. Expert Rev Neurother. 2006;6(1):47-56.

64. Velligan DI, Mahurin RK, Diamond PL, et al. The functional significance of symptomatology and cognitive function in schizophrenia. Schizophr Res. 1997;25(1):21-31.

65. Lencz T, Smith CW, McLaughlin D, et al. Generalized and specific neurocognitive deficits in prodromal schizophrenia. Biol Psychiatry. 2006;59(9):863-871.

66. Knable MB, Weinberger DR. Dopamine, the prefrontal cortex and schizophrenia. J Psychopharmacol. 1997;11:123-131.

67. Goldman-Rakic PS, Muly EC 3rd, Williams GV. D(1) receptors in prefrontal cells and circuits. Brain Res Brain Res Rev. 2000;31: 295-301.

68. Davis KL, Kahn RS, Ko G, Davidson M. Dopamine in schizophrenia: a review and reconceptualization. Am J Psychiatry. 1991;148: 1474-1486.

69. Weinberger DR. Implications of normal brain development for the pathogenesis of schizophrenia. Arch Gen Psychiatry. 1987;44: 660-669.

70. Mnie-Filali O, Dahan L, Zimmer L, Haddjeri N. Effects of the serotonin 5-HT(7) receptor antagonist SB-269970 on the inhibition of dopamine neuronal firing induced by amphetamine. Eur J Pharmacol. 2007;570:72-76.

71. Cifariello A, Pompili A, Gasbarri A. 5-HT(7) receptors in the modulation of cognitive processes. Behav Brain Res. 2008;195(1):171-179.

72. Meneses A. 5-HT system and cognition. Neurosci Biobehav Rev. 1999;23:1111-1125.

73. Meneses A. A pharmacological analysis of an associative learning task: function of 5-HT1 to 5-HT7 receptor subtypes on a Pavlovian/ instrumental autoshaped memory. Learn Mem. 2003;10:363-372.

74. Meneses A, Manuel-Apolinar L, Rocha L, Castello E, Castello C. Expression of the 5-HT receptors in rat brain during memory consolidation. Behav Brain Res. 2004;152:425-436.

75. Bonaventure P, Nepomuceno D, Hein L, Sutcliffe JG, Lovenberg T, Hedlund PB. Radioligand binding analysis of knockout mice reveals 5-hydroxytryptamine(7) receptor distribution and uncovers 8-hydroxy2-(di-n-propylamino)tetralin interaction with alpha(2) adrenergic receptors. Neuroscience. 2004;4:901-911.

76. Plassat JL, Amlaiky N, Hen R. Molecular cloning of a mammalian serotonin receptor that activates adenylate cyclase. Mol Pharmacol. $1993 ; 2: 229-236$

77. Martín-Cora FJ, Pazos A. Autoradiographic distribution of 5-HT7 receptors in the human brain using $[3 \mathrm{H}]$ mesulergine: comparison to other mammalian species. Br J Pharmacol. 2004;1:92-104.

78. Latuda [prescribing information]. Marlborough, MA: Sunovion Pharmaceuticals; Dec 2011. Available from: http://www.latuda.com/ LatudaPrescribingInformation.pdf. Accessed Dec 20, 2011.
Drug Design, Development and Therapy

\section{Publish your work in this journal}

Drug Design, Development and Therapy is an international, peerreviewed open-access journal that spans the spectrum of drug design and development through to clinical applications. Clinical outcomes, patient safety, and programs for the development and effective, safe, and sustained use of medicines are a feature of the journal, which

\section{Dovepress}

has also been accepted for indexing on PubMed Central. The manuscript management system is completely online and includes a very quick and fair peer-review system, which is all easy to use. Visit http://www.dovepress.com/testimonials.php to read real quotes from published authors. 